Disponível em

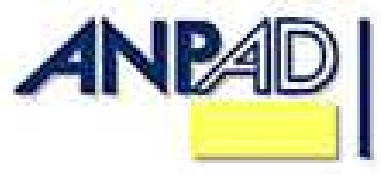

http://www.anpad.org.br/rac

RAC, Rio de Janeiro, v. 16, n. 4, art. 5, pp. 586-607, Jul./Ago. 2012

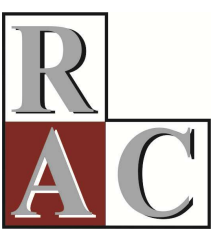

\title{
Configurações Estratégicas de Firmas Brasileiras de Alto Desempenho Listadas na BM\&FBOVESPA
}

Organizational Configurations of High Performance Brazilian Companies Listed on the BM\&FBOVESPA Securities, Commodities, and Futures Exchange

Maria Cristina do Amaral Gurgel *

E-mail: cristinagurgel@uol.com.br Fundação Getúlio Vargas - EAESP/FGV

São Paulo, SP, Brasil.

Flávio Carvalho de Vasconcelos

E-mail: flavio.vasconcelos@fgv.br Fundação Getúlio Vargas - EBAPE/FGV Rio de Janeiro, RJ, Brasil.

* Endereço: Maria Cristina do Amaral Gurgel

Rua Bueno Brandão, 134, São Paulo/SP, 04509-020.

Copyright (C) 2012 RAC. Todos os direitos, até mesmo de tradução, são reservados. É permitido citar parte de artigos sem autorização prévia, desde que seja identificada a fonte. 


\title{
Resumo
}

Este estudo parte da premissa teórica de que firmas obtêm lucros extraordinários quando exploram imperfeições de mercado. Imperfeições são tratadas como variáveis causais para identificar configurações de empresas de alto desempenho listadas na BM\&FBovespa entre 2005 e 2009. O estudo, qualitativo comparativo, adota uma metodologia replicável, a saber: (a) análise categorial de conteúdo semântico de relatórios emitidos por Corretoras de Valores sobre as empresas selecionadas; e (b) análise dos dados através da abordagem MDSO (Most Different Similar Outcome) da Qualitative Comparative Analysis (QCA). A metodologia permite tratar causalidade complexa com pouco número de casos. Neste estudo, possibilitou reduzir dezenove variáveis a poucas causas comuns e conjuntamente necessárias ao desempenho de quinze empresas. Os resultados mostram três configurações alternativas ao alto desempenho. A primeira é formada por poucas imperfeições exploradas por concessões de serviços públicos. A segunda, por sua vez, é formada por empresas exclusivas, que fabricam bens com demanda crescente, heterogêneos e diferenciáveis. A terceira configuração faz-se por empresas gigantes, que fabricam e comercializam produtos com demanda inelástica e generalizada. Acumulam ativos que raramente se tornam obsoletos, formando poderosos monopólios ou oligopólios mundiais.

Palavras-chave: configurações organizacionais; imperfeições de mercado; desempenho superior da firma; Qualitative Comparative Analysis (QCA).

\begin{abstract}
The objective of this work was to explore the theoretical premise that companies are able to obtain extraordinary profit levels by exploiting market imperfections. To this end, market imperfections are treated as causal variables in order to identify organizational configurations of high-performing companies listed on the Brazilian BM\&FBovespa securities, commodities and futures exchange between 2005 and 2009. The research methodology combines (a) MDSO (Most Different Similar Outcome) approach of Qualitative Comparative Analysis (QCA) to find organizational configurations with (b) Semantic and Categorical Content Analysis for exploring reports produced by stock broking firms about the companies of interest. This approach allows for analysis of complex causality even with a small number of cases. Nineteen variables responsible for the high performance of fifteen companies were able to be attributed to only a few common causalities. Results show three alternative configurations of market imperfections for attaining high performance. The first configuration combines few market imperfections exploited by government regulated companies. The second configuration is composed of exclusive companies producing differentiated, heterogeneous products for high demand markets. The third configuration contains oversize companies producing commodities characterized by their almost inelastic demand. Their low obsolescence rate of assets generates powerful local monopolies and global oligopolies.
\end{abstract}

Key words: organizational configurations; market imperfections; superior firm performance; Qualitative Comparative Analysis (QCA). 


\section{Introdução}

Em seu artigo Types of Competition and the Theory of Strategy: Toward a Integrative Framework, Barney (1986a) sugere que os conceitos da competição Schumpeteriana, Chamberliniana e da Organização Industrial, que sustentam as principais correntes teóricas do campo da Estratégia Empresarial, poderiam ser integrados em uma única teoria. Essa integração teórica permitiria às empresas encontrar o modelo que melhor correspondesse a seu tipo de competição.

A exploração de imperfeições de mercado para a obtenção de lucros extraordinários é a base teórica comum a todos os tipos de competição (Barney, 1986b). Assim, o estudo de suas configurações possibilita verificar se há relação entre as taxonomias estratégicas empíricas e as premissas dos três tipos de competição apontadas por Barney (1986a).

Para identificar configurações, adotamos a Teoria de Configurações Organizacionais (Short, Payne, \& Ketchen, 2008), assumindo que empresas podem explorar combinações similares de imperfeições de mercado para obter lucros extraordinários. Porém, diferentemente da visão de Porter (1978, 1979), que busca grupos estratégicos contidos em um setor econômico específico, partimos da premissa de que grupos estratégicos podem conter empresas de diferentes setores, porém com características competitivas similares. Assim, adotamos como universo de análise as empresas brasileiras de alto desempenho listadas na BMF\&Bovespa entre os anos 2005 e 2009, sem distinção setorial. As configurações da exploração de suas imperfeições de mercado foram identificadas através da Análise Qualitativa Comparativa (QCA) desenvolvida por Charles Ragin (Ragin, 2008; Rihoux \& Ragin, 2009).

$\mathrm{Na}$ seção seguinte, discutiremos o uso do QCA como ferramenta metodológica para a identificação de Configurações Organizacionais; no capítulo 3, a adequação da ferramenta ao universo estudado, assimétrico devido principalmente aos monopólios de alto desempenho. O capítulo 4 trata da seleção dos casos típicos de alto desempenho; já os capítulos 5 e 6 , da análise categorial de conteúdo semântico, ferramenta utilizada para a coleta de informações qualitativas secundárias. No capítulo 7, encontra-se o resumo das etapas realizadas no tratamento dos dados pelo programa fsQCA 2.0 (Ragin, Drass, \& Davey, 2006); e, no capítulo 8, os resultados da pesquisa e os comentários finais.

\section{Configurações Organizacionais, Imperfeições de Mercado e o QCA}

Os estudos sobre Configurações, notadamente sobre Grupos Estratégicos, são de grande importância para a pesquisa de Estratégia Empresarial, porém tem perdido espaço na literatura do campo devido à carência de rigor teórico e empírico refletidos em seus resultados (Fiss, 2007). Empiricamente, até hoje não se pode provar que Grupos Estratégicos sejam reais, nem falsificar a tese de que não são produtos artificiais criados pela Análise de Clusters (Hatten \& Hatten, 1987; McGee \& Thomas, 1986; Osborne, Stubbart, \& Ramaprasad, 2001; Tang \& Thomas, 1992; Thomas \& Venkatraman, 1988). Os estudos também não se utilizam de uma base teórica comum (Barney \& Hoskisson, 1990; Osborne et al., 2001; Short, Ketchen, Palmer, \& Hult, 2007; Thomas \& Venkatraman, 1988). Assim, a escolha das variáveis, as interpretações dos construtos e a não robustez dos resultados geram pouco ou nenhum consenso sobre as relações causais entre as configurações encontradas e o desempenho (Bacharach, 1989; Barney \& Hoskinson, 1990; Hoskisson, Hitt, Wan, \& Yiu, 1999).

Fiss (2007) defende que as limitações desses estudos são fruto da falta de correspondência entre método e teoria. Configurações Organizacionais têm relações constitutivas com causalidade complexa, relações não lineares e não simétricas. Para identificar esses tipos de relações, Fiss (2007) sugere o uso da teoria dos conjuntos encontradas na metodologia QCA desenvolvida para o campo das Ciências Políticas por Charles Ragin (Ragin, 2008; Rihoux \& Ragin, 2009). No modelo mais simples, o Crisp 
$Q C A$, transformam-se as variáveis em unidades dicotômicas indicando seu pertencimento ou não a um conjunto, conforme as premissas da álgebra booleana de falso (0) ou verdadeiro (1). Técnicas mais avançadas, como o Multi-Value QCA e o Fuzzy QCA, permitem o uso de variáveis intervalares.

Em sua base, o QCA visa identificar duas premissas essenciais às hipóteses de causalidade de um fenômeno: necessidade e suficiência (causas únicas de um fenômeno são necessárias e suficientes à sua ocorrência; causas combinadas são necessárias, mas unitariamente insuficientes à ocorrência de um fenômeno). Para isso, reduz-se a complexidade através da álgebra booleana contida no algoritmo Quine-McCluskey (Ragin et al., 2006). Esse algoritmo utiliza duas regras da pesquisa indutiva dos Métodos de Mill (Mill, 1852): a da concordância e a da diferença. A regra da concordância pode ser assim descrita: se duas ou mais instâncias de um fenômeno sob investigação têm apenas uma circunstância em comum, esta será a causa ou o efeito do fenômeno. Em contraste, a regra da diferença elimina variáveis que se apresentam em casos nos quais não há ocorrência do fenômeno (Mill, 1852; Rihoux \& Ragin, 2009). Assim, se um fenômeno ocorre em uma instância e não em outra, e as duas têm todas as circunstâncias em comum exceto uma, presente na primeira e não na segunda, tal circunstância é o efeito ou causa do fenômeno (Mill, 1852; Rihoux \& Ragin, 2009).

Métodos que utilizam dessas regras básicas são considerados quase experimentais, já que os resultados dependem da capacidade de isolar fatores verdadeiramente relevantes. Não são dedutivos e capazes de provar uma relação causal, já que não há controle sobre outros fatores além dos estudados (Rihoux \& Ragin, 2009). Contudo, são ferramentas valiosas às Ciências Sociais, pois possibilitam a eliminação de fatores irrelevantes ou de falsas hipóteses, estando de acordo com o princípio de falsificação de Popper (Popper, 1959).

Além da possibilidade de redução da complexidade, o QCA permite identificar situações em que existam: (a) causalidade complexa, (b) causalidade assimétrica, (c) relações não lineares, (d) equifinalidade e (e) multifinalidade.

A causalidade complexa, chamada por Rihoux e Ragin (2009) de causalidade múltipla conjuntural, considera que cada caso individual é uma combinação complexa de propriedades, um todo específico que não poder ser perdido em desmembramentos de variáveis.

O pressuposto da assimetria causal é a essência do QCA e existe quando a ocorrência de um fenômeno e a sua não ocorrência requerem análises separadas e explicações diversas. Utilizando-se de um exemplo de Ragin (2008, p. 15): se considerarmos duas afirmações, (a) países desenvolvidos são democráticos e (b) diversos países não desenvolvidos também são democráticos, para que haja correlação, a segunda afirmação deveria ser (c) países não desenvolvidos não são democráticos. Porém, pela teoria de conjuntos, as duas primeiras afirmações são constitutivas e perfeitamente relacionadas: países desenvolvidos é um subconjunto de países democráticos. Isso significa que ser um país desenvolvido é um fator suficiente para a existência da democracia, porém não é um fator necessário.

O QCA considera que as relações sejam não lineares, como ocorre nas análises de correlação. Como as relações são constitutivas, um fator não tem o mesmo efeito incremental na ocorrência de um fenômeno (Berg-Schlosser, De Meur, Rihoux, \& Ragin, 2009).

O QCA é uma técnica a ser utilizada quando há a premissa de equifinalidade, ou seja, quando há casos nos quais diferentes combinações de fatores podem gerar o mesmo fenômeno. Assim, a combinação de condições é suficiente, mas não necessária à existência de um fenômeno, já que padrões alternativos podem gerar resultados semelhantes (Rihoux \& Ragin, 2009).

A multifinalidade, inversamente à equifinalidade, existe quando uma mesma condição puder gerar resultados diferentes em contextos ou tempos diversos, ou seja, seu resultado é contextual.

Além das particularidades acima listadas, o QCA também rejeita qualquer forma permanente de causalidade, e pressupõe que condições que expliquem apenas um caso são tão importantes quanto as que explicam vários casos, já que implicam em diversidade causal (Ragin, 1987). Porém, em comum 
com todas as técnicas quantitativas, o QCA admite o postulado de que existam regularidades causais nos fenômenos sociais (Ragin, 1987; Rihoux \& Ragin, 2009).

A Tabela 1 resume as principais semelhanças e diferenças entre a metodologia QCA e os tradicionais métodos quantitativos utilizados no campo das Ciências Sociais.

Tabela 1

\section{Premissas do QCA e Métodos Quantitativos}

\begin{tabular}{ll}
\hline TÉCNICAS QUANTITATIVAS & QCA \\
\hline Exige robustez teórica. & Exige robustez teórica. \\
Evita explicações individuais. & Evita explicações individuais. \\
Ferramenta replicável e formalizada & Ferramenta replicável e formalizada \\
Amostra aleatória & Seleção intencional dos casos, para incluir casos típicos. \\
Generalização estatística & Generalização modesta, limitada no tempo e no espaço. \\
Causalidade única ou múltipla & Causalidade múltipla conjuntural \\
Universalidade ou equifinalidade & Equifinalidade \\
Unifinalidade. & Multifinalidade \\
Relações lineares causais e aditividade & Relações constitutivas e não aditivas \\
Simetria causal & Assimetria causal \\
$\begin{array}{l}\text { Desmembra os casos em um conjunto de variáveis } \\
\text { independentes. }\end{array}$ & $\begin{array}{l}\text { Desmembra casos em um conjunto de atributos inter- } \\
\text { relacionados. }\end{array}$ \\
$\begin{array}{l}\text { Foco nas variáveis e nas relações entre variáveis } \\
\text { causais e dependentes. }\end{array}$ & $\begin{array}{l}\text { Foco em configurações de variáveis que resultem em } \\
\text { diferentes resultados. }\end{array}$ \\
$\begin{array}{l}\text { Número de vezes que a variável independente é } \\
\text { observada é relevante (quantificação das }\end{array}$ & $\begin{array}{l}\text { Número de observações dos atributos não é relevante } \\
\text { ocorrências). }\end{array}$ \\
\hline
\end{tabular}

Nota. Fonte: Elaborado pelos autores a partir do resumo de Rihoux, B., \& Ragin, C. C. (2009). Configurational comparative methods. Thousand Oaks: Sage Publications, Inc. e Ragin, C. C. (2008). Redesigning social inquiry: fuzzy sets and beyond. Chicago: University of Chicago Press.

É verdade que, havendo amostras suficientes, técnicas estatísticas como a análise fatorial e a análise discriminante permitem identificar casos de equifinalidade, porém, pressupõem causalidade simétrica. É verdade também que o uso da álgebra booleana parece primário frente à possibilidade de uso de avançadas técnicas estatísticas (Ragin, 2008), porém, permite encontrar relações não identificáveis por essas técnicas de pesquisa. King, Keohane e Verba (1994) criticam a comum (e aqui utilizada) técnica de selecionar casos pela variável dependente e procurar condições causais compartilhadas entre múltiplas instâncias com o mesmo resultado. Para esses autores, abandonar essa prática é um dos elementos necessários para conciliar técnicas qualitativas às quantitativas.

Porém, estudos que se utilizam da metodologia QCA evidenciam a não necessidade de sua conciliação com as técnicas quantitativas, pois esta é melhor utilizada quando as variáveis explicativas não são independentes. Chamberlin (1956), que desenvolveu a Teoria de Competição Monopolística, é feliz em mostrar a necessidade de se considerar interações complexas entre imperfeições de mercado. Afirma que a combinação de elementos de monopólio se assemelha a um processo químico em que não é possível se pressupor aditividade: "Slight elements of monopoly have a way of playing unexpected logical tricks, with results quite out of proportion to their seeming importance" (Chamberlin,1956, p. 3). 


\section{Assimetria Causal e o Método QCA}

Definidas as premissas e as questões da pesquisa - quais falhas as empresas brasileiras de alto desempenho exploram e a que tipo de competição suas configurações pertencem - este estudo tinha inicialmente pretensões exploratórias e integrativas, coerentes com a proposta de Barney (1986a). Porém, decidido o universo da análise - empresas listadas na BM\&FBovespa - a primeira constatação marcante foi a existência de diversas concessões e empresas monopolistas dentre as de maior desempenho contábil. Na introdução da versão brasileira de seu livro intitulado Competição, Porter (1999, p. 7) lembra que a ausência de competição é uma característica de países em desenvolvimento, como no passado dos países desenvolvidos, cuja economia sofria "sufocante intervenção governamental" e pressões de "ostensivos cartéis" que "embotavam a competição". Assim, a metodologia a ser utilizada teria obrigatoriamente que contemplar monopólios, concedidos ou conquistados pelo poder da própria empresa. No entanto, a maioria dos estudos empíricos quantitativos sobre desempenho das firmas no Brasil parte da mesma premissa adotada por autores estrangeiros de que a economia é competitiva e que monopólios, cartéis e proteção governamental podem ser descartados da análise. É o caso dos estudos de decomposição da variância, cuja metodologia obriga a eliminação de empresas monopolistas e duopolistas, que concluem que o efeito setor também não é importante para o desempenho de empresas brasileiras (Bandeira-de-Mello \& Marcon, 2004).

O QCA normalmente é utilizado para tratar simultaneamente casos com resultados positivos e negativos, através da regra de concordância e da diferença (Mill, 1852; Ragin, 1987; Rihoux \& Ragin, 2009). Mas, dada uma situação de assimetria causal, a ferramenta foi utilizada para tratar casos positivos buscando encontrar similaridades em sistemas heterogêneos (Most Different, Similar Outcome [MDSO]), contrapondo-os a apenas um caso negativo teórico: o mercado perfeito (causa e efeitos ausentes). A análise MDSO da metodologia QCA parte do pressuposto de que as populações diferenciam-se apenas em um número restrito de variáveis e que diferenças não podem explicar similaridades (Przwolrski \& Teune, 1970). O contraste dos casos elimina os fatores observados que não são comuns aos casos selecionados. Os fatores comuns são, portanto, isolados como possíveis causas do resultado estudado.

Tomada isoladamente, a metodologia MDSO não cumpre as etapas do método quaseexperimental de Mill (Mill, 1852). Para conhecer a verdadeira relação entre causa e efeito, é necessário estudar as condições nas quais a causa está presente sem a consequência (Anckar, 2005), o que exige a confrontação com casos semelhantes e de resultado ausente (Most Similar, Different Outcome [MSDO]). Porém, essa confrontação exige simetria causal, além da existência de casos semelhantes com resultados diferentes para serem confrontados, o que não é o caso das empresas monopolistas. Assim, dada a limitação do modelo, seguimos o conselho de tratar quinze casos, o mínimo para que o método seja válido (Berg-Schlosser \& De Meur, 2009).

A inovação desse estudo em relação ao MSDO proposto por Berg-Schlosser e De Meur (2009) é a confrontação dos casos positivos com um caso teórico negativo, o que possibilita tratar os dados com o uso do programa fsQCA 2.0 (Ragin et al., 2006), ao invés das matrizes de distância sugeridas pelos autores (Berg-Schlosser \& De Meur; 2009).

Porém, qual é a diferença do resultado deste estudo em relação ao método completo, o quase experimental? A resposta exige a explicação por partes e foi obtida pelos autores, a partir da análise de resultados de simulações de seis variáveis (A, B, C, D, E e F):

1. No método QCA, a determinação de uma causa pode ser subdividida em dois conceitos complementares: necessidade e suficiência. Na causalidade complexa, tem-se que cada causa é necessária, mas unitariamente insuficiente à ocorrência de um fenômeno. Quando se comparam apenas resultados positivos, encontram-se as causas necessárias, compartilhadas entre todos os casos (Berg-Schlosser \& De Meur; 2009; Ragin, 1987; Rihoux \& Ragin, 2009). 
2. Quando o programa é utilizado com casos positivos e negativos, a suficiência pode ou não ser encontrada. Por exemplo, um grupo de empresas combinou as variáveis A, B, C, D, E e F e obteve sucesso. Uma empresa combinou as variáveis $\mathrm{A}, \mathrm{B}, \mathrm{C}$ e $\mathrm{D}$ e não obteve sucesso. Tem-se que $\mathrm{A} * \mathrm{~B} * \mathrm{C} * \mathrm{D}$ (na álgebra booleana o símbolo + significa OU e o símbolo * significa E) é uma condição causal necessária, mas insuficiente para o desempenho. Tem-se também que $\mathrm{A} * \mathrm{~B} * \mathrm{C} * \mathrm{D} * \mathrm{E} * \mathrm{~F}$ é uma condição causal necessária e suficiente para o desempenho. Mas não se sabe se $\mathrm{A} * \mathrm{~B} * \mathrm{C} * \mathrm{D} * \mathrm{E}$ é uma condição causal suficiente, pois não existem casos com essa configuração. Assim, existe uma margem de dúvida sobre a suficiência ou não desta combinação intermediária.

3. Quando o programa é utilizado apenas com casos positivos, confrontando-os com apenas um caso negativo teórico (fatores ausentes, resultado ausente), é necessário pressupor-se que apenas a fórmula mais complexa seja suficiente e necessária ao desempenho. Não se pode saber se a empresa atingiria um resultado semelhante se combinasse menos variáveis.

4. Portanto, respondendo à questão, o método adotado indetermina a suficiência (o que também pode ocorrer com o método completo como visto no item (2)). Contudo, isso não é um problema se assumirmos a premissa de incerteza. Em um mundo sem incertezas, uma empresa pode reduzir a complexidade a uma configuração mínima necessária a seu desempenho. Em um mundo incerto, a empresa sempre terá que combinar um número maior de fatores, pois em algum momento essa combinação foi ou será suficiente para gerar um resultado positivo. Assim, essa metodologia não permite identificar os efeitos da adição ou da subtração das imperfeições de mercado na emergência do alto desempenho.

\section{Seleção das Empresas de Alto Desempenho}

A falta de consenso teórico em relação aos objetivos das empresas e à consequente métrica do desempenho faz com que a escolha dos seus indicadores dependa da proposta de cada estudo (Bandeira-de-Melo \& Marcon, 2004). Como este estudo é exploratório e inaugura o uso da metodologia QCA para identificação de falhas de mercado, adota uma dimensão de desempenho primária - a rentabilidade operacional (média do Lucro Operacional sobre Ativos) - uma exigência mínima que permitirá comparações posteriores com medidas multidimensionais. Também, como este trabalho se propõe a estudar a cauda superior da curva do desempenho, foram selecionadas, como casos típicos, as empresas que apresentaram coeficientes de rentabilidade operacional acima de um desvio-padrão da média de empresas listadas na BMF\&Bovespa durante o período.

É importante notar que estudos qualitativos não requerem o uso de modelos estatísticos para a seleção dos casos. Porém, dado o tamanho do universo de trezentas e vinte e quatro empresas e a natureza da variável dependente (desempenho contábil), o uso da análise estatística facilitou a identificação de casos realmente típicos de alto desempenho.

Da base de dados Economática, foram extraídos dados contábeis entre os anos 2005 e 2009 das empresas listadas na BM\&FBovespa. Do total de trezentas e vinte e quatro empresas listadas, quarenta e sete (instituições financeiras, fundos de participação e holdings) foram excluídas por apresentarem resultados contábeis não comparáveis. Outras quarenta e seis foram eliminadas pela descontinuidade de dados nos anos analisados. Também foram excluídas três empresas classificadas como outliers negativos quanto à rentabilidade, restando duzentos e vinte e oito empresas pré-selecionadas. A média da rentabilidade operacional dessas, considerado o período 2005/2009, foi de 0,077, com desvio padrão de 0,095. As vinte e seis empresas com rentabilidade operacional acima de um desvio padrão foram consideradas como de "alto desempenho". Dessas, quatro tiveram desempenho instável, com desvio padrão acima de 0,15 e foram eliminadas do grupo. Também, foram eliminadas empresas com Patrimônio Líquido negativo. Mais cinco empresas tiveram que ser suprimidas por falta de cobertura de analistas ou por terem sofrido processo de aquisição durante o período da análise. Finalmente, a CPFL Piratininga e a CPFL foram unificadas, o que levou a uma seleção final de quinze empresas. 
Verificou-se, por fim, que as quinze empresas selecionadas apresentaram uma média de LL/AT (lucro líquido sobre ativos) e LL/PL (lucro líquido sobre patrimônio liquido), entre 2005 e 2009, acima da média da totalidade das empresas listadas na BMF\&Bovespa. Esses indicadores confirmam a adequação da seleção desses casos como de alto desempenho contábil. Também, é interessante perceber que o período selecionado inclui a crise econômica mundial de 2007-2008, com reflexos ainda em 2009. Assim, essas empresas foram, inclusive, aquelas que mantiveram alto desempenho frente às instabilidades geradas pela crise.

Tabela 2

\section{Empresas Selecionadas como Casos Típicos de Alto Desempenho}

\begin{tabular}{|c|c|c|c|c|c|c|}
\hline $\begin{array}{l}\text { Classifi- } \\
\text { cação }\end{array}$ & Nome & Classificação Setorial Bovespa & $\begin{array}{l}\text { Média } \\
\text { LO/AT }\end{array}$ & $\begin{array}{l}\text { DP da } \\
\text { média } \\
\text { LO/AT }\end{array}$ & $\begin{array}{l}\text { Média } \\
\text { LL/A }\end{array}$ & $\begin{array}{l}\text { Média } \\
\text { LL/PL }\end{array}$ \\
\hline 1 & AES Tietê & Utilidade Pública / Energia Elétrica / Energia Elétrica & 0,438 & 0,070 & 0,268 & 1,323 \\
\hline 2 & Souza Cruz & Consumo não Cíclico / Fumo / Cigarros e Fumo & 0,371 & 0,104 & 0,281 & 0,571 \\
\hline 3 & Natura & $\begin{array}{l}\text { Consumo não Cíclico / Produtos de Uso Pessoal e de } \\
\text { Limpeza / Produtos de Uso Pessoal }\end{array}$ & $\mathbf{0 , 3 5 6}$ & 0,029 & 0,263 & 0,701 \\
\hline 4 & $\begin{array}{l}\text { American } \\
\text { Banknote }\end{array}$ & Bens Industriais / Serviços / Serviços Diversos & $\mathbf{0 , 2 5 0}$ & 0,088 & 0,171 & 0,254 \\
\hline 5 & Confab & $\begin{array}{l}\text { Materiais Básicos / Siderurgia e Metalurgia / } \\
\text { Artefatos de Ferro e Aço }\end{array}$ & $\mathbf{0 , 2 3 4}$ & 0,108 & 0,162 & 0,282 \\
\hline 6 & Comgás & Utilidade Pública / Gás / Gás & 0,228 & 0,039 & 0,127 & 0,384 \\
\hline 7 & Tractebel & Utilidade Pública / Energia Elétrica / Energia Elétrica & 0,226 & 0,025 & 0,150 & 0,346 \\
\hline \multirow[t]{2}{*}{8} & $\begin{array}{l}\text { CPFL } \\
\text { Piratininga }\end{array}$ & Utilidade Pública / Energia Elétrica / Energia Elétrica & 0,224 & 0,068 & 0,140 & 1,100 \\
\hline & CPFL & Utilidade Pública / Energia Elétrica / Energia Elétrica & 0,190 & 0,052 & 0,120 & 0,937 \\
\hline 9 & CCR & $\begin{array}{l}\text { Construção e Transporte / Transporte / Exploração de } \\
\text { Rodovias }\end{array}$ & 0,221 & 0,038 & 0,122 & 0,349 \\
\hline 10 & Telesp & Telecomunicações / Telefonia Fixa / Telefonia Fixa & 0,195 & 0,026 & 0,128 & 0,242 \\
\hline 11 & Eternit & $\begin{array}{l}\text { Construção e Transporte / Construção e Engenharia / } \\
\text { Materiais de Construção }\end{array}$ & 0,181 & 0,071 & 0,138 & 0,205 \\
\hline 12 & $\begin{array}{l}\text { Iochpe- } \\
\text { Maxion }\end{array}$ & $\begin{array}{l}\text { Bens Industriais / Material de Transporte / Material } \\
\text { Rodoviário }\end{array}$ & $\mathbf{0 , 1 7 8}$ & 0,072 & 0,101 & 0,273 \\
\hline 13 & Petrobras & $\begin{array}{l}\text { Petróleo, Gás e Biocombustíveis / Petróleo, Gás e } \\
\text { Biocombustíveis / Exploração e/ou Refino }\end{array}$ & $\mathbf{0 , 1 7 7}$ & 0,034 & 0,108 & 0,235 \\
\hline 14 & Vale & Materiais Básicos / Mineração / Minerais Metálicos & $\mathbf{0 , 1 7 7}$ & 0,076 & 0,125 & 0,291 \\
\hline 15 & Usiminas & $\begin{array}{l}\text { Materiais Básicos / Siderurgia e Metalurgia / } \\
\text { Siderurgia }\end{array}$ & $\mathbf{0 , 1 7 6}$ & 0,085 & 0,134 & 0,249 \\
\hline
\end{tabular}

\section{Análise Categorial de Conteúdo Semântico}

A Análise de Conteúdo é uma técnica de pesquisa que visa descrever sistemática e objetivamente um conteúdo manifesto da comunicação, tornando-o passível de tratamentos quantitativos (Bailey, 1994; Manning \& Cullum-Swan, 1998). Na versão categorial, parte-se de um conjunto de categorias exaustivas e verifica-se se a categoria é observada e em qual frequência, nos documentos estudados (Bailey, 1994). Essa técnica permite utilizar como unidade de análise tanto palavras como frases ou temas manifestos. Diferentemente da versão tradicional da metodologia de 
Análise de Conteúdo, que usa a palavra como unidade de análise, a versão semântica parte da identificação de sentidos expressos em unidades linguísticas superiores (Dellagnelo \& Silva, 2005). Apesar do uso da palavra como unidade de análise permitir sua contagem e o uso de recursos estatísticos dos métodos quantitativos, a palavra é uma unidade de significação simples, que restringe a identificação de informações presentes em substituições linguísticas complexas. Na versão semântica da metodologia, identificam-se, em frases, enunciados e discursos, combinações e substituições semânticas que comunicam mensagens semelhantes, bem como mensagens implícitas. Para captá-las, pesquisadores devem pressupor que seu repertório semântico se sobreponha ao dos autores, e que tenha capacidade de interpretar sistemas específicos, locais e temporais da linguagem em uso (Bardin, 1994). Assim, ignorando o paradigma da compartimentalização científica que cria oposição entre funcionalismo e interpretacionismo (Burrel \& Morgan, 1979), o uso da versão semântica permite adotar a premissa ontológica de que a realidade é, simultaneamente, objetiva e subjetiva. Pressupõe que fenômenos sociais existem independentemente do conhecimento que se tem sobre eles, mas que seus significados dependem de estruturas interpretativas que não podem ser perfeitamente observadas. Quanto à premissa epistemológica, defende-se que o discurso é tanto individual quanto da coletividade, que dele se apropria de forma sucessiva e recursiva (Dellagnelo \& Silva, 2005; Pagés \& Bonetti, 1987).

\section{Categorização}

Neste trabalho, a Análise de Conteúdo foi feita através da categorização prévia das variáveis (Bailey, 1994) - as imperfeições de mercado - resumidas na Tabela 3.

Tabela 3

Resumo das Variáveis e Questionário de Pesquisa

\begin{tabular}{|c|c|c|c|c|c|}
\hline Grupo & & $\begin{array}{l}\text { Código } \\
\text { Variável }\end{array}$ & Variável & $\begin{array}{l}\text { Pertenci- } \\
\text { mento } \\
\text { Crisp }\end{array}$ & Descrição grau de pertencimento (multivalor) \\
\hline \multirow{6}{*}{$\begin{array}{l}\overline{\bar{t}} \\
\dot{0}\end{array}$} & 1 & MONO & Concentração & $\begin{array}{l}\text { (3) e (2) } \\
\text { Sim } \\
(1) \text { e }(0) \\
\text { Não }\end{array}$ & $\begin{array}{l}\text { A EMPRESA é (3) monopolista; (2) oligopolista ou possui } \\
\text { market share >50\% em mercados de competição } \\
\text { monopolista; (1) líder de mercado no core business; (0) NDA. }\end{array}$ \\
\hline & 2 & SIZE & Tamanho & $\begin{array}{l}\text { (2) e (1) } \\
\text { Sim } \\
(0) \text { Não }\end{array}$ & $\begin{array}{l}\text { A EMPRESA é uma (2) empresa de grande porte (baixos } \\
\text { custos, alto poder de barganha, ampla cobertura de mercado); } \\
\text { (1) grande porte, mas não tem poder de barganha com } \\
\text { clientes OU é grande em relação aos concorrentes; (0) NDA. }\end{array}$ \\
\hline & 3 & GROUP & Tamanho Grupo & $\begin{array}{l}\text { (2) e (1) } \\
\text { Sim } \\
\text { (0) Não }\end{array}$ & $\begin{array}{l}\text { A EMPRESA tem, como acionista, (2) empresas de grande } \\
\text { porte, com alto poder de barganha e cobertura de mercado, } \\
\text { (1) empresas de grande porte no Brasil, (0) NDA. }\end{array}$ \\
\hline & 4 & DIVER & Diversificação & $\begin{array}{l}\text { (2) e (1) } \\
\text { Sim } \\
\text { (0) Não }\end{array}$ & $\begin{array}{l}\text { A EMPRESA tem (2) linha diversificada e abrangente de } \\
\text { produtos; (1) linha diversificada no mesmo segmento, (0) } \\
\text { NDA. }\end{array}$ \\
\hline & 5 & INTEG & Integração Vertical & $\begin{array}{l}\text { (2) e (1) } \\
\text { Sim } \\
(0) \text { Não }\end{array}$ & $\begin{array}{l}\text { A EMPRESA é (2) integrada verticalmente, a montante e a } \\
\text { jusante; (1) integrada montante ou jusante, (0) NDA. }\end{array}$ \\
\hline & 6 & ALIAN & Alianças Horizontais & $\begin{array}{l}\text { (2) e (1) } \\
\text { Sim } \\
\text { (0) Não }\end{array}$ & $\begin{array}{l}\text { A EMPRESA tem (2) alianças importantes com empresas do } \\
\text { mesmo setor; (1) alianças pouco representativas, (0) NDA. }\end{array}$ \\
\hline
\end{tabular}


Tabela 3 (continuação)

\begin{tabular}{|c|c|c|c|c|c|}
\hline Grupo & & $\begin{array}{l}\text { Código } \\
\text { Variável }\end{array}$ & Variável & $\begin{array}{l}\text { Pertenci- } \\
\text { mento } \\
\text { Crisp }\end{array}$ & Descrição grau de pertencimento (multivalor) \\
\hline \multirow{6}{*}{ 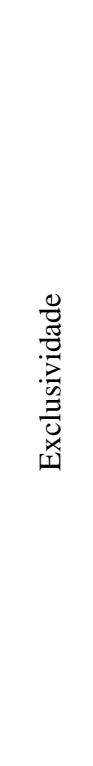 } & 7 & RESOU & $\begin{array}{l}\text { Recursos (Físicos, } \\
\text { Processos, Qualidade) }\end{array}$ & $\begin{array}{l}\text { (2) e (1) } \\
\text { Sim } \\
(0) \text { Não }\end{array}$ & $\begin{array}{l}\text { A EMPRESA possui (2) recursos tecnológicos e qualidade } \\
\text { superiores; (1) economias de escala e escopo importantes; (0) } \\
\text { NDA. }\end{array}$ \\
\hline & 8 & MANAG & Humanos e Gerencias & $\begin{array}{l}\text { (2) e (1) } \\
\text { Sim } \\
\text { (0) Não }\end{array}$ & $\begin{array}{l}\text { A EMPRESA possui (2) recursos gerenciais superiores; (1) } \\
\text { competentes em economias de custos; (0) NDA. }\end{array}$ \\
\hline & 9 & DIFER & $\begin{array}{l}\text { Diferenciação de } \\
\quad \text { Produtos }\end{array}$ & $\begin{array}{l}\text { (2) e (1) } \\
\text { Sim } \\
(0) \text { Não }\end{array}$ & $\begin{array}{l}\text { A EMPRESA tem (2) produtos hedônicos diferenciados; (1) } \\
\text { produtos técnicos diferenciados; (0) NDA. }\end{array}$ \\
\hline & 10 & LEGIT & $\begin{array}{l}\text { Recursos de } \\
\text { Legitimidade }\end{array}$ & $\begin{array}{l}\text { (2) e (1) } \\
\text { Sim } \\
(0) \text { Não }\end{array}$ & $\begin{array}{l}\text { A EMPRESA possui (2) legitimidade com impacto nos } \\
\text { custos; (1) adoção de boas práticas: (0) NDA. }\end{array}$ \\
\hline & 11 & LOCAL & $\begin{array}{l}\text { Recursos de } \\
\text { Rede/Localidade }\end{array}$ & $\begin{array}{l}\text { (2) e (1) } \\
\text { Sim } \\
(0) \text { Não }\end{array}$ & $\begin{array}{l}\text { A EMPRESA é uma (2) empresa com atuação mundial; (1) } \\
\text { com implantação em outros países ou exportadora, ou tem } \\
\text { multinacionais como acionistas; (0) NDA. }\end{array}$ \\
\hline & 12 & RAWM & Acesso MP & $\begin{array}{l}\text { (2) e (1) } \\
\text { Sim } \\
(0) \text { Não }\end{array}$ & $\begin{array}{l}\text { A EMPRESA tem (2) acesso exclusivo a matérias primas } \\
\text { com qualidade superior; (1) acesso privilegiado; (0) NDA }\end{array}$ \\
\hline \multirow{6}{*}{$\frac{0}{\frac{\pi}{0}}$} & 13 & DEMAND & $\begin{array}{l}\text { Crescimento da } \\
\text { demanda }\end{array}$ & $\begin{array}{l}\text { (2) e (1) } \\
\text { Sim } \\
\text { (0) Não }\end{array}$ & $\begin{array}{l}\text { Os resultados da Empresa foram (2) afetados positivamente } \\
\text { graças ao crescimento da demanda por todo período; (1) } \\
\text { exceto na crise; (0) NDA. }\end{array}$ \\
\hline & 14 & GROWTH & $\begin{array}{l}\text { Crescimento } \\
\text { (Orgânico) }\end{array}$ & $\begin{array}{l}\text { (2) e (1) } \\
\text { Sim } \\
(0) \text { Não }\end{array}$ & $\begin{array}{l}\text { A EMPRESA (2) cresceu muito organicamente no período; } \\
\text { (1) expandiu a capacidade; (0) NDA. }\end{array}$ \\
\hline & 15 & AQUIS & Fusões/ Aquisições & $\begin{array}{l}\text { (2) e (1) } \\
\text { Sim } \\
(0) \text { Não }\end{array}$ & $\begin{array}{l}\text { A EMPRESA (2) cresceu muito por fusões e aquisições; (1) } \\
\text { fez algumas aquisições; (0) NDA. }\end{array}$ \\
\hline & 16 & ADAPT & $\begin{array}{l}\text { Adaptação/Capacidades } \\
\text { dinâmicas }\end{array}$ & $\begin{array}{l}\text { (2) e (1) } \\
\text { Sim } \\
(0) \text { Não }\end{array}$ & $\begin{array}{l}\text { A EMPRESA mostrou (2) grande capacidade de antecipação } \\
\text { (lançamento de novos produtos, aquisições, reestruturaçôes } \\
\text { e/ou reposicionamentos de mercado); (1) adaptação, porém } \\
\text { com limitada mobilidade de fatores; (0) NDA. }\end{array}$ \\
\hline & 17 & INOV & Inovação & $\begin{array}{l}\text { (2) e (1) } \\
\text { Sim } \\
(0) \text { Não }\end{array}$ & $\begin{array}{l}\text { A EMPRESA (2) destaca-se pela inovação em produtos e/ou } \\
\text { processos; (1) investe em melhorias de processos*; (0) NDA. }\end{array}$ \\
\hline & 18 & LUCK & Sorte/ Incerteza & $\begin{array}{l}\text { (2) e (1) } \\
\text { Sim } \\
(0) \text { Não }\end{array}$ & $\begin{array}{l}\text { A EMPRESA (2) apresentou resultados relevantes positivos } \\
\text { não esperados, devido a mudanças no ambiente do negócio; (1) } \\
\text { parte do resultado (câmbio, etc.) favorável; (0) NDA. }\end{array}$ \\
\hline 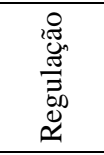 & 19 & GOV & Governo & $\begin{array}{l}\text { (2) e (1) } \\
\text { Sim } \\
\text { (0) Não }\end{array}$ & $\begin{array}{l}\text { A EMPRESA (2) é uma concessão; (2) recebeu incentivos } \\
\text { ou proteções governamentais, concessões, vantagens } \\
\text { tributárias diretas ou indiretas favoráveis; (0) NDA. }\end{array}$ \\
\hline
\end{tabular}

Essas variáveis são frutos de um levantamento exaustivo das premissas do mercado perfeito e das teorias que tratam da quebra dessas premissas (Gurgel, 2011).

Dados secundários sobre a exploração de falhas de mercado foram obtidos através da leitura de relatórios empresariais, gerados entre os anos 2005 e 2009 por corretoras de valores ou bancos de investimentos. O conteúdo dos relatórios sobre cada empresa selecionada foi compilado em um quadro e organizado cronologicamente. Garantiu-se que, para cada empresa, houvesse relatórios de ao menos três corretoras distintas. Todos dados contábeis e suas análises foram excluídos, a não ser quando apresentados em forma de texto. Gerado um arquivo para cada empresa, 371 relatórios foram lidos e interpretados. Frases que indicam a exploração de falhas de mercado foram: (a) identificadas por 
números e realçadas em negrito; (b) a elas foram conferidos rótulos conforme variáveis definidas na fase de categorização; e (c) identificadas em uma coluna criada especificamente para esse fim. Imediatamente após a leitura dos relatórios, foram preenchidas as fichas com variáveis de respostas dicotômicas multivalores, transformadas em dicotômicas posteriormente (Tabela 3). A escala multivalor foi criada após a leitura dos textos. Isso permitiu identificar diferenças em grau entre as empresas e melhorou o ponto de corte para as variáveis dicotômicas. Dois doutores em Estratégia Empresarial realizaram o mesmo procedimento com três empresas: Souza Cruz, CCR e Iochpe Maxion. Essas empresas foram escolhidas por representarem as três configurações de empresas encontradas após o tratamento dos dados. Considerando variáveis dicotômicas, a concordância para as variáveis da Souza Cruz foi de $84 \%$ após revisão. A concordância referente à CCR foi de $89 \%$ e da Iochpe-Maxion $68 \%$ após a revisão.

\section{Tratamento dos Dados}

\section{Fase 1: Pressuposto da homogeneidade externa}

Nesta fase de análise, todas as empresas foram tratadas conjuntamente, pressupondo-se que elas participem do mesmo ambiente econômico, ou seja, que condições externas não variem. As dezenove variáveis analisadas permitem um total de quinhentos e vinte e quatro mil, duzentas e oitenta e oito configurações $\left(2^{19}\right)$, complexidade não suportada pelo sistema. Assim, os dados foram tratados por partes, ou seja, por conjuntos de falhas (De Meur \& Gottcheiner, 2009).

\section{Conjunto de falhas PODER}

Os dados foram tabulados, transformados em dicotômicos em uma planilha Excel e importados pelo programa fsQCA 2.0 (Ragin et al., 2006). Um caso negativo teórico foi criado para corresponder à configuração da competição perfeita, na qual não há falhas de mercado e, consequentemente, não há lucros extraordinários. Após escolhida opção de análise CrispSet, as variáveis relativas ao grupo Poder foram selecionadas na Figura Select Variables, gerando uma Truth Table. Tal tabela lista todas as combinações possíveis de variáveis $\left(2^{\mathrm{n}}\right)$; identifica quais delas foram apresentadas nos dados fornecidos; e em que frequência (number). Apresenta também o resultado de cada configuração e as contradições (combinações diferentes com resultados iguais). Utilizando-se a Standard Analysis, o programa pergunta se as ausências dos fatores podem influenciar o resultado positivamente; no caso, não. O programa trata os dados com o algoritmo QUINE-MCCLUSKEY e apresenta três soluções. A solução complexa pouco reduz as variáveis. Considera que: (a) a ausência de uma variável pode contribuir para o resultado positivo; e que: (b) todas as configurações possíveis não verificadas na amostra (no caso $2^{6}-10$ ) não geram resultados positivos. Já, a solução parcimoniosa reduz a complexidade ao mínimo considerando que: (a) as variáveis são independentes; (b) a ausência de uma variável não pode contribuir para o resultado positivo; e que (c) o resultado das configurações não verificadas não importa, ou seja, pode ser positivo ou negativo. Finalmente, a solução intermediária é gerada a partir da verificação dos pares configuracionais das variáveis encontradas pela solução parcimoniosa, pressupondo multifinalidade.

Nessa fase, somente a solução parcimoniosa é considerada e mostra que as empresas precisam apresentar a condição SIZE ou a condição DIVER para alcançar desempenho superior (WIN). 
Tabela 4

Resultado da Análise das Variáveis PODER

\begin{tabular}{lcc}
\hline & Raw coverage & Unique coverage \\
\hline COMPLEX SOLUTION & & \\
$\sim$ size* group*diver* ${ }^{*}$ integ*alian & 0,13 & 0,13 \\
mono*size*group* diver*alian & 0,27 & 0,13 \\
$\sim$ mono*size* group*diver*integ & 0,13 & 0,13 \\
mono*size*group*diver*alian & 0,33 & 0,13 \\
$\sim$ mono*size*group*diver*integ* alian & 0,07 & 0,07 \\
mono*size*group*integ* alian & 0,20 & 0,0 \\
mono*size*group*diver*integ & 0,27 & 0,0 \\
\hline PARSIMONIOUS SOLUTION & & \\
size & 0,87 & 0,27 \\
diver & 0,73 & 0,13 \\
\hline INTERMEDIATE SOLUTION & & \\
alian*diver & 0,53 & 0.13 \\
integ*diver*size & 0,40 & 0,07 \\
diver*group*size & 0,47 & 0,07 \\
group*size*mono & 0,67 & 0,27 \\
\hline
\end{tabular}

\section{Conjunto de falhas exclusividade, agilidade e regulação}

O mesmo procedimento foi utilizado para tratar o grupo de condições Exclusividade. Os resultados da solução parcimoniosa e intermediária apresentam uma única variável: local. Isso mostra que ela não se agrega a outras variáveis do grupo Exclusividade. O programa foi rodado novamente sem a condição local e verificou-se que a condição resou (Recursos) cobre a totalidade dos outros casos, sem interagir novamente com as outras variáveis do conjunto em questão. A solução parcimoniosa do grupo de condições Agilidade mostra a grande importância da variável demand. $\mathrm{O}$ grupo Regulação possui apenas uma condição, que é a intervenção governamental (GOV).

\section{Consolidaçâo da fase 1}

Somando-se a condição GOV com as condições necessárias minimizadas pelas análise parcimoniosa, têm-se seis condições necessárias à condição win (desempenho superior). São elas : size, diver, local, resou, demand e gov. Isso reduz as possibilidades configuracionais de 524.288 para 64, ou seja, reduz a complexidade em $99,9878 \%$ do modelo inicial. Se considerarmos que as variáveis são independentes, a solução parcimoniosa mostra que é necessário explorar uma das cinco condições causais, ou seja:

$$
\text { local + demand }+ \text { size }+ \text { resou }+ \text { gov }
$$

Se considerarmos que há multifinalidade, a análise intermediária mostra que as empresas selecionadas utilizaram-se de três configurações mínimas, considerando-se as variáveis encontradas na solução parcimoniosa, necessárias para o alto desempenho:

$$
\text { size*demand*gov + diver*resou*local*demand + size*resou*local*gov }
$$




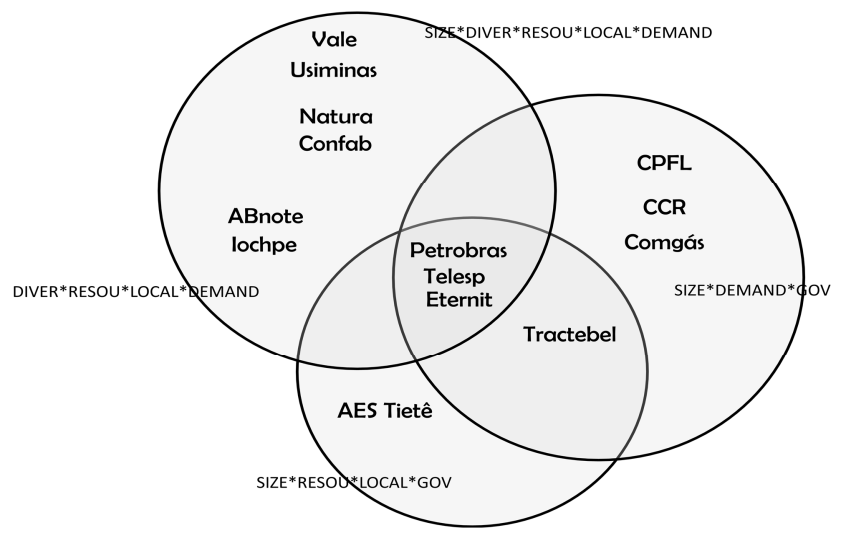

Figura 1. Conjuntos de Configurações Necessárias para Desempenho Superior (FASE 1).

Os resultados mostram a importância do governo para o desempenho de oito empresas. Para as concessionárias, o governo é normativo e atua como regulador. Define o regime de preços, autoriza, ou não, a extensão de prazos de concessão, concede mais concessões a grandes grupos. Algumas concessionárias são livres para negociar parte de seus serviços, porém, o regime em que isso ocorre também é regulado e sujeito a alterações. Para empresas que atuam no mercado concorrencial, o governo age através de seu poder interventor, concedendo incentivos fiscais que alteram preços e demanda. Duas cadeias produtivas, representadas pelas empresas analisadas, foram afetadas por políticas intervencionistas no período analisado: a cadeia da construção civil e a cadeia da indústria automobilística. O Estado também atua como empresário, competindo com empresas privadas, caso representado aqui pela Petrobras. Isso faz com que o governo também aja através de seu poder de gastar, como cliente de empresas, como a Confab.

\section{Fase 2: pressuposto heterogeneidade externa}

A regra da minimização da álgebra booleana pressupõe que não haja fatores externos que interfiram na ocorrência do fenômeno. Apesar de ser tratada, na fase anterior, como uma variável, a intervenção governamental na economia não é apenas uma falha de mercado. A ação do governo altera o regime econômico e, consequentemente, as regras do jogo. Os resultados da fase 1 mostraram que, no Brasil, convivem o regime econômico sob regulação e o regime semilivre, que também conta com a participação do Estado como empresário e interventor. Na fase 2, as empresas que atuam no mercado semilivre são tratadas separadamente das concessionárias. As variáveis foram divididas em dois grupos. Essa opção permitiu tratar simultaneamente as variáveis resultantes das soluções intermediárias, o que não foi possível na fase 1 .

Tabela 5

Redução das Condições Causais (Etapa 1 com Grupo 1 de Variáveis)

\begin{tabular}{lcc}
\hline & Raw coverage & Unique coverage \\
\hline MERCADO SEMILIVRE & & \\
\hline PARSIMONIOUS SOLUTION & 1,00 & 1,00 \\
diver & & \\
\hline INTERMEDIATE SOLUTION & 0,33 & 0,11 \\
size*group*diver*growth & 0,44 & 0,22 \\
diver*alian*growth*aquis & 0,44 & 0,22 \\
size*diver*integ*rawm*growth & 0,44 & 0,22 \\
mono*size*group*diver*integ*rawm & & \\
\hline
\end{tabular}


Talela 5 (continuação)

\begin{tabular}{lcc}
\hline CONCESSÕES & Raw coverage & Unique coverage \\
\hline PARSIMONIOUS SOLUTION & & \\
mono & 1,00 & 0,00 \\
size & 1,00 & 0,00 \\
group & 1,00 & 0,00 \\
\hline INTERMEDIATE SOLUTION & & 0,17 \\
mono*size*group*integ & 0,33 & 0,33 \\
mono*size*group*growth & 0,67 & 0,17 \\
mono*size*group*diver*alian*aquis & 0,33 & \\
\hline
\end{tabular}

Nota. Resultados do tratamento das variáveis: MONO, SIZE, GROUP, DIVER, INTEG, ALIAN, RAWM, GROWTH, AQUIS.

Tabela 6

Redução das Condições Causais (Etapa 1 com Grupo 2 de Variáveis)

\begin{tabular}{lcc}
\hline & Raw coverage & Unique coverage \\
\hline MERCADO SEMILIVRE & & \\
\hline PARSIMONIOUS SOLUTION & 1,00 & 0,00 \\
luck & 1,00 & 0,00 \\
demand & 1,00 & 0,00 \\
local & 1,00 & 0,00 \\
resour & & \\
\hline INTERMEDIATE SOLUTION & 0,56 & 0,11 \\
resou*legit*local*demand*luck & 0,67 & 0,22 \\
resou*local*demand*inov*luck & 0,56 & 0,22 \\
resou*manag*difer*local*demand*adapt*luck & & \\
\hline CONCESSÕES & & 0,16 \\
\hline PARSIMONIOUS SOLUTION & 0,83 & 0,00 \\
demand & 0,50 & 0,00 \\
resou & 0,50 & 0,00 \\
manag & 0,83 & \\
local & & 0,16 \\
\hline INTERMEDIATE SOLUTION & 0,83 & 0,17 \\
demand & 0,50 & \\
resou*manag*local & & \\
\hline
\end{tabular}

Nota. Resultados do tratamento das variáveis: RESOU, MANAG, DIFER, LEGIT, LOCAL, DEMAND, ADAPT, INOV, LUCK. 
Tabela 7

Redução das Condições Causais (Etapa 2 com Solução Parcimoniosa da Etapa 1)

\begin{tabular}{lcc}
\hline \multicolumn{1}{l}{ Raw coverage } & Unique coverage \\
\hline MERCADO SEMILIVRE & & \\
\hline PARSIMONIOUS SOLUTION & 1,00 & 0,00 \\
luck & 1,00 & 0,00 \\
demand & 1,00 & 0,00 \\
local & 1,00 & 1,00 \\
resour & 1,00 & 0,00 \\
diver & & \\
\hline INTERMEDIATE SOLUTION & 1,00 & 1,00 \\
diver*resou*local*demand*luck & & \\
\hline CONCESSÕES & & 0,00 \\
PARSIMONIOUS SOLUTION & 1,00 & 0,00 \\
mono & 1,00 & 0,00 \\
size & 1,00 & \\
group & & 0,57 \\
INTERMEDIATE SOLUTION & 0,86 & 0,14 \\
mono*size*group*demand & 0,43 & \\
mono*size*group*resou*manag*local &
\end{tabular}

Nota. Consolidado com resultados da solução parcimoniosa das etapas 1 e 2, conforme Tabelas 5 e 6.

Tabela 8

Redução das Condições Causais (Etapa 2 com Solução Intermediária da Etapa 1)

\begin{tabular}{lcc}
\hline MERCADO SEMILIVRE & $\begin{array}{c}\text { Raw } \\
\text { coverage }\end{array}$ & $\begin{array}{c}\text { Unique } \\
\text { coverage }\end{array}$ \\
\hline AS GIGANTES & & \\
\hline PARSIMONIOUS SOLUTION & & \\
mono & 1,00 & 1,00 \\
size & 1,00 & 1,00 \\
group & 1,00 & 1,00 \\
diver & 1,00 & 1,00 \\
integ & 1,00 & 1,00 \\
resou & 1,00 & 1,00 \\
local & 1,00 & 1,00 \\
rawm & 1,00 & 1,00 \\
demand & 1,00 & 1,00 \\
luck & 1,00 & 1,00 \\
\hline & & Continua
\end{tabular}




\begin{tabular}{|c|c|c|}
\hline & $\begin{array}{l}\text { Raw } \\
\text { coverage }\end{array}$ & $\begin{array}{l}\text { Unique } \\
\text { coverage }\end{array}$ \\
\hline \multicolumn{3}{|l|}{ MERCADO SEMILIVRE } \\
\hline \multicolumn{3}{|l|}{ AS GIGANTES } \\
\hline \multicolumn{3}{|l|}{ INTERMEDIATE SOLUTION } \\
\hline mono*size*group*diver*integ*resou*local*rawm*demand*luck*adapt*difer*manag & 0,50 & 0,25 \\
\hline mono*size*group*diver*integ*resou*local*rawm*demand*luck*aquis*legit*alian & 0,50 & 0,25 \\
\hline $\begin{array}{l}\text { mono*size*group*diver*integ*resou*local*rawm*demand*luck*inov*aquis*growth* } \\
\text { alian }\end{array}$ & 0,50 & 0,25 \\
\hline \multicolumn{3}{|l|}{ AS EXCLUSIVAS } \\
\hline \multicolumn{3}{|l|}{ PARSIMONIOUS SOLUTION } \\
\hline diver & 1,00 & 1,00 \\
\hline resou & 1,00 & 1,00 \\
\hline difer & 1,00 & 1,00 \\
\hline local & 1,00 & 1,00 \\
\hline demand & 1,00 & 1,00 \\
\hline growth & 1,00 & 1,00 \\
\hline luck & 1,00 & 1,00 \\
\hline inov & 0,80 & 0,00 \\
\hline adapt & 0,80 & 0,00 \\
\hline manag & 0,80 & 0,00 \\
\hline size & 0,60 & 0,00 \\
\hline \multicolumn{3}{|l|}{ INTERMEDIATE SOLUTION } \\
\hline size*diver*resou* manag $*$ difer $*$ local $*$ demand $*$ growth*inov*luck & 0,40 & 0,20 \\
\hline size*diver* integ* resou*manag*difer*local *rawm *demand *growth* adapt *luck & 0,40 & 0,20 \\
\hline diver *alian*resou*difer* legit*local*demand*growth*aquis *adapt* inov *luck & 0,40 & 0,40 \\
\hline \multicolumn{3}{|l|}{ CONCESSÕES } \\
\hline \multicolumn{3}{|l|}{ PARSIMONIOUS SOLUTION } \\
\hline mono & 1,00 & 0,00 \\
\hline size & 1,00 & 0,00 \\
\hline group & 1,00 & 0,00 \\
\hline \multicolumn{3}{|l|}{ INTERMEDIATE SOLUTION } \\
\hline mono*size*group*local $*$ demand $*$ growth & 0,50 & 0,33 \\
\hline mono*size*group*integ*resou*manag*local & 0,17 & 0,17 \\
\hline mono*size*group*alian*local*demand*aquis & 0,33 & 0,17 \\
\hline mono*size* group*integ*demand*growth*aquis & 0,17 & 0,17 \\
\hline
\end{tabular}

Nota. Consolidado com resultados da solução intermediária da etapa 1 (Tabelas 5 e 6). 


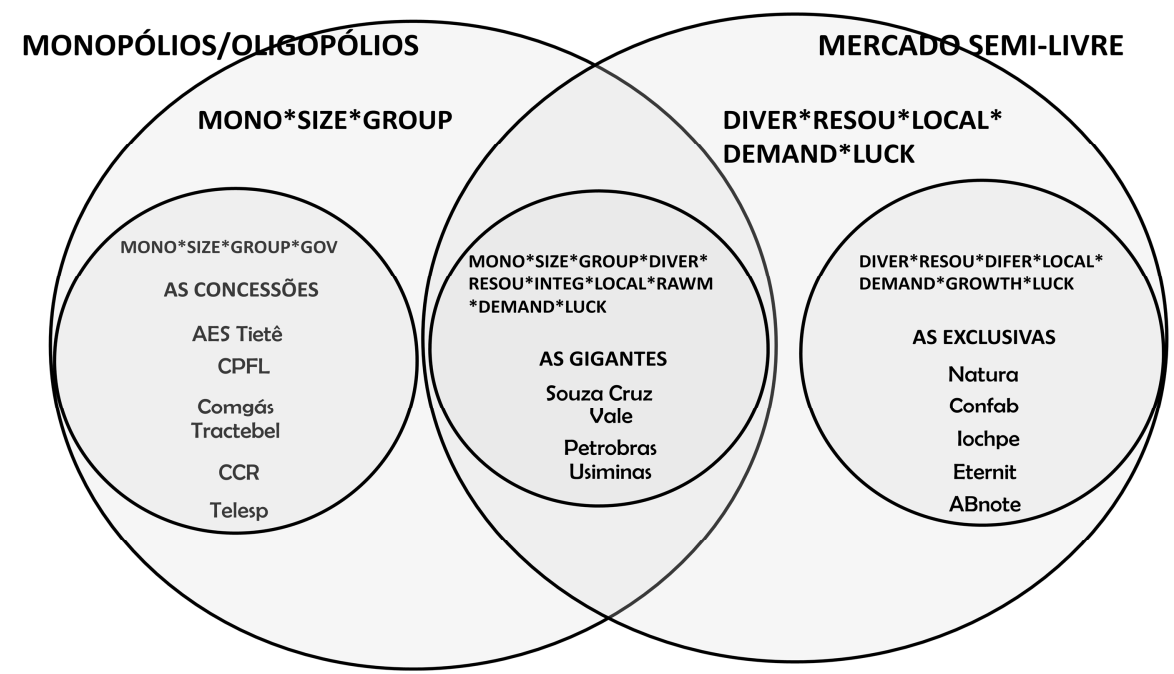

Figura 2. Conjuntos de Falhas Alternativamente Necessárias ao Alto Desempenho.

\section{Resultados e Discussão}

As configurações encontradas na fase 1 mostram a importância do governo em determinar as falhas de mercado exploradas por empresas de alto desempenho. Os resultados da fase 2 mostram que essas empresas formam três configurações que operam em duas superestruturas econômicas. Essas superestruturas, o regime de monopólio/oligopólio e o regime quase-livre determinam, em parte, as estratégias competitivas, uma vez que limitam a variedade de configurações viáveis. Porém, diferentemente do paradigma Stucture - Conduct - Performance (SCP), os dados mostram que a estrutura não determina o desempenho, pois empresas podem configurar, com equifinalidade, falhas de mercado para obtenção de lucros extraordinários.

Entre as quinze empresas analisadas, seis são concessões: AES Tietê, CPFL, Comgás, Tractebel, CCR e Telesp. Essas compartilham três imperfeições de mercado necessárias a seu desempenho, além da intervenção governamental: concentração, tamanho e o tamanho do grupo. $\mathrm{O}$ governo regulador cria impedimentos à mobilidade de fatores, ou seja, barreiras de entrada que permitem a obtenção de rendas de monopólio por parte dos regulados. O tamanho permite ganho de escala e escopo em setores industriais de capital intensivo, explicação coerente às linhas estratégicas do SCP e das Teorias de Recursos. Porém, chama atenção a necessidade compartilhada dessas empresas de pertencerem a grandes grupos empresariais nacionais e estrangeiros. A AES Tietê, por exemplo, tem como acionista a Brasiliana Holding cujo controle está nas mãos da AES Corporation e do BNDES. A AES Corporation é um dos maiores grupos de energia do mundo e se associa ao próprio governo brasileiro no controle acionário da companhia. Em janeiro de 2006, a AES Tietê negociou com a AES Eletropaulo, controlada também pela Brasiliana Holding, e que consome 100\% da energia gerada, contratos bilaterais no valor de $\mathrm{R} \$ 132,73 / \mathrm{MWh}$, enquanto a Tractebel vendia sua energia a $\mathrm{R} \$ 85,69 / \mathrm{MWh}$. Isso explica seu desempenho operacional, o maior entre todas as empresas listadas na bolsa. Já a CPFL tem como acionistas a VBC Energia S/A, a 521 Participações S/A e a Bonaire Participações S/A, sendo a VBC Energia S/A uma empresa do Grupo Votorantim, Camargo Corrêa e BNDES. A 521 Participações S/A é um fundo da PREVI, dos funcionários do Banco do Brasil. A Bonaire Participações é um fundo de funcionários de empresas, que inclui o fundo da própria CESP (Funcesp). De forma interessante, a CPFL adquiriu um grande número de concessões durante o período analisado - Santa Cruz, CMS Energy Brasil, Empresa Bandeirante de Energia, CPFL Piratininga - integrando suas operações e fortalecendo sua posição no setor de energia. A Camargo Corrêa também é sócia da Andrade Gutierrez na CCR, que igualmente cresceu através de aquisições e novas concessões. 
Confirmando a importância dos grupos empresariais no desempenho das concessões, David Parker (2003) mostra que, no Reino Unido, o desempenho pós-privatização das firmas reguladas não pode ser isolado dos efeitos da propriedade (ownership), competição, regulação e mudança tecnológica. Mostra, também, que concessões estão sujeitas a riscos regulatórios além dos comerciais, e que a dinâmica de regulação envolve ambas as partes, regulador e regulado. $\mathrm{O}$ último, para ter sucesso, aprende a adotar estratégias ótimas frente ao órgão regulador.

Em Capitalismo de Laços, Sergio Lazzarini (2011) desvenda as relações de propriedade que envolvem o governo brasileiro, grandes grupos nacionais e estrangeiros. Utilizando-se da técnica de análise de redes, identifica conexões políticas privilegiadas que permitiram a essas empresas transformar riscos regulatórios em vantagens para suas próprias empresas: obter recursos diferenciados como capital público, diversos tipos de proteção e "outras vantagens não disponíveis a empreendedores menos conectados" (Lazzarini, 2011, p. 11).

As nove empresas que atuam na superestrutura do regime quase-livre têm como fatores comuns três imperfeições de mercado internas à firma (diversificação, recursos, localidade) e duas ambientais (demanda em crescimento e sorte).

Além dessas imperfeições, as quatro gigantes (Petrobras, Vale, Usiminas e Souza Cruz), que formam uma configuração de relação constitutiva com as duas superestruturas encontradas - mercado de monopólios/oligopólios e mercado quase-livre -, exploram, de forma comum, mais cinco falhas de mercado: concentração, tamanho, tamanho do grupo, integração vertical e acesso privilegiado a matérias-primas. Nota-se que essas imperfeições estão sob seu controle e referem-se primordialmente ao grupo de variáveis Poder. O desempenho dessas firmas pode facilmente ser explicado pelas teorias tanto da linha SCP quanto de Recursos, já que o tamanho, a concentração e o acesso privilegiado a recursos escassos são fatores de heterogeneidade que permitem criar barreiras eficientes de entrada e obter rendas de monopólio. Porém, essas teorias partem da premissa do equilíbrio estável e tratam as empresas como sistemas fechados, cujos perímetros coincidem com os de seus países sede, incompatíveis com a exploração das falhas localidade e demanda em crescimento. Assim, as teorias que visam explicar os fenômenos de monopólio e oligopólio no Brasil devem incorporar a análise de imperfeições espaciais e o efeito tempo. Empresas podem decidir restringir espacialmente seu mercado e aumentar seu poder monopolista ou expandi-lo e atuar de forma mais competitiva (Greenhut, Norman, \& Hung, 1987). É interessante notar que a exploração de imperfeições espaciais permitiu a essas empresas atender mercados que menos sofreram com a crise, reduzindo as perdas durante esse período. A internacionalização também permitiu criar estratégias para atender mercados de demanda crescente. É o caso da Souza Cruz, que, com a demanda estável no Brasil, aumentou suas exportações de fumo e cigarro para países emergentes. Um aspecto fundamental compartilhado por essas empresas é a característica de seus produtos. Petrobras, Vale, Usiminas e Souza Cruz fabricam e comercializam produtos com demanda pouco elástica, generalizada e sem substitutos próximos. Produtos com essas características, cujos consumidores não buscam inovações, mas preço e constância de qualidade, permitem às empresas melhorarem tecnologias, processos e acumularem ativos que raramente se tornam obsoletos. O mesmo não acontece com empresas que fabricam bens diferenciáveis, com substitutos menos imperfeitos, como é o caso do subconjunto das seis empresas restantes de alto desempenho - as exclusivas - que operam na superestrutura do mercado semilivre (Confab, Eternit, Natura, Iochpe e ABNote). Essas empresas compartilham as imperfeições diversificação, recursos, diferenciação, demanda em crescimento, crescimento orgânico e sorte. Nota-se que o desempenho superior dessas firmas se sustenta por sua heterogeneidade, fornecendo produtos diferenciados, destinados a demandas específicas. Buscam, através do crescimento orgânico e da diversificação, suprir mercados com demandas crescentes. Essas empresas contaram também com a sorte, principalmente na época de crise, quando o ambiente se tornou adverso e pouco previsível. A exploração dessas falhas de mercado é contemplada de forma bastante satisfatória pelo ramo da Teoria de Recursos, que trata das Capacidades Dinâmicas das Empresas (Dynamic Capabilities).

Em suma, este estudo mostra que a combinação de falhas de mercado exploradas por empresas abertas brasileiras de alto desempenho é contingencial à estrutura do mercado e às características dos produtos, ou seja, a diversidade estratégica é limitada por essas variáveis. Porém, é importante 
observar que o grau de limitação da diversidade varia em função da estrutura de mercado e do tempo. Também, não há o pressuposto de que as opções estratégicas viáveis sejam poucas, já que há uma grande variedade de imperfeições de mercado a serem exploradas. Assim, essas restrições estão longe de caracterizar uma situação determinística, na qual a Estratégia Empresarial se tornaria desnecessária e disfuncional.

Apenas uma estrutura de mercado no Brasil corresponde às estruturas apontadas por Barney (1986a): a Chamberliniana, de Competição Monopolística, na qual atuam empresas com bens diferenciados. Suas curvas de oferta e demanda se sobrepõem de forma imperfeita às dos produtos concorrentes. Suas rendas superiores são primordialmente de origem ricardianas (vezes do empreendedor e vezes da sorte) de forma coerente à Teoria das Capacidades Dinâmicas do empreendedor e da sorte, coerentes aos trabalhos da Teoria das Capacidades Dinâmicas (Brown \& Eisenhardt, 1997; Itami \& Roehl, 1987; Mahoney \& Pandian, 1992; Prahalad \& Hamel, 1990; Schoemaker, 1992).

Ou seja, empresas com produtos de demanda inelástica tendem a formar monopólios e oligopólios e gerar fortes barreiras de entrada através da acumulação de ativos. $\mathrm{O}$ alto desempenho dessas empresas é explicado pelas rendas de monopólio e pelas rendas ricardianas advindas das economias de escala e escopo. Essa explicação está de acordo com as premissas da Organização Industrial citadas por Barney (1986a). Porém, sua competição é internacional e suas imperfeições têm fortes características espaciais. Essas empresas exploram monopólios locais e expandem-se internacionalmente atuando simultaneamente em mercado competitivos e de demanda crescente, o que lhes exige recursos superiores outros que economias de escala e escopo.

Já concessões de serviços públicos têm seu desempenho superior explicado por suas rendas de monopólio, fato também de acordo com as premissas da Organização Industrial. Mas, sujeitas a mudanças de regulação, seu sucesso também se explica pelo poder dos acionistas, que atuam na esfera institucional para transformar riscos regulatórios em vantagens para suas empresas.

Neste estudo, não foi encontrado nenhum caso de alto desempenho em regime Schumpeteriano. Pesquisas complementares poderiam identificar se a destruição criativa tem impedido a geração de lucros extraordinários das empresas brasileiras que operam sob esse regime competitivo.

Metodologicamente, esta pesquisa traz diversas contribuições ao campo da Estratégia Empresarial: (a) transpõe as barreiras dos setores, envelopes não naturais criados por classificações industriais (Short et al., 2008; Thomas \& Venkatraman, 1988); (b) utiliza imperfeições de mercado como variáveis, ao partir da premissa mais robusta e central das teorias em Estratégia Empresarial, em que empresas precisam explorar imperfeições de mercado para obter lucros extraordinários; (c) emprega variáveis qualitativas, obtidas através da técnica de Análise Categorial de Conteúdo Semântico, que possibilitou identificar fatores multidimensionais não encontrados em dados quantitativos; (d) introduz a Análise Qualitativa Comparativa (Qualitative Comparative Analysis QCA) como ferramenta de análise configuracional conforme sugestão de Fiss (2007); e, finalmente, (e) combina etapas metodológicas passíveis de réplica em estudos futuros. Tais estudos, a saber: (a) levantamento de informações sobre desempenho de empresas na base Economática; (b) utilização dos construtos de imperfeições de mercado como variáveis; (c) Análise Categorial de Conteúdo Semântico de relatórios emitidos por Bancos de Investimento e Corretoras de Valores; e (d) análise dos dados através da metodologia QCA/MDSO e do programa fsQCA 2.0 (Ragin, 2008; Rihoux \& Ragin, 2009; Ragin et al., 2006).

Contudo, diversos estudos podem complementar os resultados desta pesquisa, focando suas limitações Em relação à variável dependente, há necessidade de se identificar as empresas que apresentem indicadores de desempenho multidimensionais. Quanto ao escopo, há necessidade de se estudar configurações de empresas com médio e baixo desempenho. Já, quanto às variáveis tácitas (recursos e capacidades dinâmicas), há necessidade de refinar os dados através de informações primárias. Finalmente, esta metodologia também pode ser replicada em outros países cujos contextos 
podem exigir configurações de explorações de imperfeições de mercado diversas às encontradas no Brasil.

Artigo recebido em 05.12.2011. Aprovado em 12.04.2012.

\section{Referências}

Anckar, D. (2005). Decentralization and island nationalism in microstates: where, how andwhy? Canadian Review of Studies in Nationalism, 32(1-2), 109-120.

Bacharach, S. B. (1989). Organizational theories: some criteria for evaluation. Academy of Management Review, 14(4), 496-515.

Bailey, K. D. (1994). Methods of social research. New York: The Free Press.

Bandeira-de-Mello, R., \& Marcon, R. (2004, setembro). A mensuração multivariada da 'performance' e suas componentes de variância: uma análise dos efeitos do ano, indústria e firma no contexto brasileiro. Anais do Encontro Nacional da Associação Nacional de Pós-Graduação e Pesquisa em Administração, Curitiba, PR, Brasil, 28.

Bardin, L. (1994). Análise de conteúdo. Lisboa, Edições 70.

Barney, J. B. (1986b). Strategic factor markets: expectations, luck, and business strategy. Management Science, 32(10), 1231-1241. doi: 10.1287/mnsc.32.10.1231

Barney, J. B. (1986a). Types of competition and the theory of strategy: toward an integrative framework. The Academy of Management Review, 11(4), 791-800. doi: 10.2307/258397

Barney, J. B., \& Hoskisson, R. E. (1990). Strategic groups: untested assertions and research proposals. Managerial \& Decision Economics, 11(3), 187-198. doi: 10.1002/mde.4090110306

Berg-Schlosser, D., \& De Meur (2009). Comparative research design, case and variable selection. In B. Rihoux \& C. C. Ragin (Eds.), Configurational comparative methods (pp. 1-18). Thousand Oaks: Sage Publications, Inc.

Berg-Schlosser, D., De Meur, G., Rihoux, B., \& Ragin, C. C. (2009). Qualitative comparative analysis (QCA) as an Approach. In B. Rihoux \& C. C. Ragin (Eds.), Configurational comparative methods (pp. 1-18). Thousand Oaks: Sage Publications, Inc.

Brown, S. L., \& Eisenhardt, K. M. (1997). The art of continuous change: linking complexity theory and time-paced evolution in relentlessly shifting organizations. Administrative Science Quarterly, 42(1), 1-34. doi: 10.2307/2393807

Burrel, G., \& Morgan, G. (1979). Elements of sociology and corporate life. London: Heinemann.

Chamberlin, E. H. (1956). The theory of monopolistic competition (5a ed.). Cambridge: Harvard University Press.

Dellagnelo, E. H. L., \& Silva, R. C. (2005). Análise de conteúdo e sua aplicação em pesquisa na administração. In M. M. F. Vieira \& D. M. Zouain (Orgs.), Pesquisa qualitativa em administração - teoria e prática (pp. 97-118). Rio de Janeiro: Fundação Getúlio Vargas.

De Meur, G., \& Gottcheiner, A. (2009). The logic and assumptions of MDSO_MSDO designs. In D. Byrne \& C. C. Ragin (Eds.), The sage handbook of case-based methods (pp. 208-211). London: Sage Publications Ltd. 
Fiss, P. C. (2007). A set-theoretic approach to organizational configurations. Academy of Management Review, 32(4), 1180-1198.

Greenhut, M., Norman, G., \& Hung, C. (1987). The economics of imperfect competition. An spatial approach. Cambridge: Cambridge University Press.

Gurgel, M. C. B. A. (2011). Configurações estratégicas de empresas brasileiras de alto desempenho: análise qualitativa comparativa das imperfeições de mercado por elas exploradas (Tese de doutorado). Escola de Administração de Empresas de São Paulo, Fundação Getúlio Vargas, São Paulo, SP, Brasil.

Hatten, K. J., \& Hatten, M. L. (1987). Strategic groups, asymmetrical mobility barriers and contestability. Strategic Management Journal, 8(4), 329-342. doi: 10.1002/smj.4250080404

Hoskisson, R. E., Hitt, M. A., Wan, W. P., \& Yiu, D. (1999). Theory and research in strategic management: swings of a pendulum. Journal of Management, 25(3), 417-456. doi: $10.1177 / 014920639902500307$

Itami, H., \& Roehl, T. W. (1987). Mobilizing invisible assets. Cambridge, MA: Harvard University Press.

King, G., Keohane, R. O., \& Verba, S. (1994). Designing social inquiry: scientific inference in qualitative research. Princeton, NJ: Princeton University Press.

Lazzarini, S. G. (2011). Capitalismo de laços. Rio de Janeiro: Elsevier Editora.

Mahoney, J. T., \& Pandian, J. R. (1992). The resource-based view within the conversation of strategic management. Strategic Management Journal, 13(5), 363-380.

Manning, P. K., \& Cullum-Swan, B. (1998). Narrative, content and semiotic analysis. In N. K. Denzin, \& Y. S. Lincoln (Eds.), Collecting and interpreting qualitative materials (pp. 246-273): Thousand Oaks, CA: Sage Publications, Inc.

McGee, J., \& Thomas, H. (1986). Strategic groups: theory, research and taxonomy. Strategic Management Journal, 7(2), 141-160. doi: 10.1002/smj.4250070204

Mill, J. S. (1852). System of logic, rationative and inductive. New York: Harper \& Brothers.

Osborne, D. J., Stubbart, C. I., \& Ramaprasad, A. (2001). Strategic groups and competitive enactment: a study of dynamic relationships between mental models and performance. Strategic Management Journal, 22(5), 435-454. doi: 10.1002/smj.166

Pagés, M., \& Bonetti, M. (1987). O poder nas organizações. São Paulo: Atlas.

Parker, D. (2003). Performance, risk and strategy in privatised, regulated industries: the UKs experience. International Journal of Public Sector Management 16(1), 75-100. doi: $10.1108 / 09513550310456436$

Popper, K. R. (1959). The logic of scientific discovery. London: Hutchinson.

Porter, M. E. (1978). Market structure, strategy formulation, and firm profitability: the theory of strategic groups and mobility barriers. In J. Cady (Ed.), Marketing and the public interest (pp. 101-126). Cambridge, Mass: Marketing Science Institute.

Porter, M. E. (1979). The structure within industries and companies performance. Review of Economics \& Statistics, 61(2), 214-227.

Porter, M. E. (1999). Competição, estratégias competitivas essenciais (12a ed.). Rio de Janeiro: Elsevier Editora. 
Prahalad, C. K., \& Hamel, G. (1990). The core competence of the corporation. Harvard Business Review, 68(3), 79-91.

Przeworski, A., \& Teune, H. (1970). The logic of comparative social inquiry. New York, NY: WileyInterscience.

Ragin, C. C. (1987). The comparative method. Moving beyond qualitative and quantitative strategies. Berkeley, Los Angeles and London: University of California Press.

Ragin, C. C. (2008). Redesigning social inquiry - fuzzy sets and beyond. Chicago: University of Chicago Press.

Ragin, C. C., Drass, K. A., \& Davey, S. (2006). [Programa de Computador]. Fuzzy-set/qualitative comparative analysis 2.0. In A. D. o. S. Tucson: University of Arizona (Ed.).

Rihoux, B., \& Ragin, C. C. (2009). Configurational comparative methods. Thousand Oaks: Sage Publications, Inc.

Schoemaker, P. J. H. (1992). How to link strategic vision to core capabilities. Sloan Management Review, 34(1), 67-81.

Short, J. C., Ketchen, D. J., Palmer, T. B., \& Hult, G. T. M. (2007). Firm, strategic group, and industry influences on performance. Strategic Management Journal, 28(2), 147-167.

Short, J. C., Payne, G. T., \& Ketchen, D. J., Jr. (2008). Research on organizational configurations: past accomplishments and future challenges. Journal of Management, 34(6), 1053-1079. doi: $10.1177 / 0149206308324324$

Tang, M.-J., \& Thomas, H. (1992). The concept of strategic groups: theoretical construct or analytical convenience. Managerial and Decision Economics, 13(4), 323-329. doi: 10.1002/mde.4090130407

Thomas, H., \& Venkatraman, N. (1988). Research on strategic groups: progress and prognosis. Journal of Management Studies, 25(6), 537-555. doi: 10.1111/j.1467-6486.1988.tb00046.x 